\title{
Studi Literatur: Model Pembelajaran Quantum Teaching Dalam Meningkatkan Keberanian Berbicara Siswa Menggunakan Media Realia
}

\author{
Thoriq Hasan Adikalan ${ }^{1 *}$ \\ 1) Program Studi Pendidikan IPA Universitas Jember
}

\begin{abstract}
One of the reasons for the low learning outcomes is that the learning method used by the teacher does not involve student activity and also the lack of care from the teacher to provide media in learning. The courage to speak a student is very important and needed in a class discussion, because with a student daring to speak in front of the class he has been found as an active student. The purpose of this article is to discuss the application of realia media in increasing the courage to speak students during learning or class discussion so as to increase student activity. Realia media is an object that can be seen, heard or experienced by students so as to provide experience directly to them. Quantum Teaching is an effective and fun and not boring learning model. Quantum Teaching learning steps are known as TANDUR: (1) Grow (2) Natural (3) Rename (4) Demonstration (5) Repeat and (6) Celebrate. Relevant research results show that Media Realia is able to increase student activity in asking, discussing, and expressing their opinions.
\end{abstract}

Keyword: Quantum Teaching, Media Realia, Speak.

\section{PENDAHULUAN}

Pendidikan nasional berfungsi mengembangkan kemampuan dan karakter pembangunan dan peradaban bangsa yang bermartabat dalam konteks kehidupan intelektual bangsa, bertujuan untuk berkembangnya potensi peserta didik agar bahkan menjadi manusia yang beriman dan takut tuhan satu Mahakuasa, berakhlak mulia, sehat, berilmu, cakap, kreatif, mandiri dan menjadi warga negara yang demokratis dan bertanggung jawab (Goman;2017).

Menurut Djamarah dan Zain (2002:143) keberhasilan proses belajar dipengaruhi oleh model pembelajaran yang dapat mengaktifkan siswa dalam aktivitas belajar. Salah satu usaha yang dapat dilakukan adalah menerapkan model pembelajaran yang mampu menciptakan lingkungan belajar yang kondusif, efektif, dan menyenangkan bagi siswa. Sehingga siswa tertarik untuk mengikuti proses belajar mengajar Slameto (2003: 92).

Media pembelajaran adalah sarana prasarana dalam mengajar dan merupakan alat bantu untuk memudahkan pendidik dalam mengaplikasikan isi kurikulum agar lebih mudah dimengerti oleh peserta didik.
Menurut Rossi dan Breidle, media adalah seluruh alat atau bahan yang dapat dipakai untuk tujuan pendidikan seperti radio, televisi, buku, koran, majalah dan sebagainya (Arsyad, 2002).

Pemanfaatan media pembelajaran dalam proses pembelajaran penting karena peserta didik dalam menerima pengalaman belajar atau mendalami materi- materi pelajarannya masih banyak memerlukan benda-benda, kejadian kejadian yang sifatnya konkret, mudah diamati, langsung diamati, sehingga pengalaman- pengalaman tersebut akan lebih mudah dipahami (Arsyad, 2002).

Arsyad menjelaskan bahwa media realia adalah benda yang dapat dilihat, didengar atau dialami oleh peserta didik sehingga memberikan pengalaman langsung kepada mereka (2002).

Quantum Teaching adalah badan ilmu pengetahuan dan metodologi yang digunakan dalam rancangan, penyajian, dan fasilitas SuperCamp, berdasarkan teori-teori pendidikan seperti Accelerated Learning (Lazanov), Multiple Intelligences (Gardner), Neuro-Linguistics Programming (Grinder dan Bandler), Experimental Learning

ScienceEdu Vol. I. No. 1 Desember 2018 
(Hahn), Socratic Inquiry, Cooperative Learning (Johnson dan Johnson), dan Elements of Effective Instruction (Hunter). Quantum Teaching merangkaikan yang paling baik dari yang terbaik menjadi sebuah paket multisensori, multi kecerdasan, dan kompatibel dengan otak, yang pada akhirnya akan melejitkan kemampuan guru untuk mengilhami dan kemampuan murid untuk berprestasi. (DePorter dkk, 2001)

Quantum Teaching memberikan kritik terhadap cara mengajar yang selama ini dilakukan secara 'turun temurun'. Persamaan Quantum Teaching ini diibaratkan mengikuti konsep Fisika Quantum yaitu:

$\mathrm{E}=\mathrm{mc} 2$

$\mathrm{E}=$ energi (antusiasme, efektivitas belajarmengajar, dan semangat) $\mathrm{m}=$ massa (semua individu yang terlibat, situasi, materi, dan fisik)

$\mathrm{c}=$ interaksi (hubungan yang tercipta di kelas) (Ridho, 2005)

Prinsip merupakan suatu pernyataan fundamental atau kebenaran yang menjadi pokok berpikir dan bertindak. Menurut De Poter (2005: 78) model quantum teaching memiliki lima prinsip yang mempengaruhi seluruh aspek quantum teaching. Prinsipprinsip model quantum teaching meliputi (1) segalanya berbicara; (2) segalanya bertujuan; (3) pengalaman sebelum pemberian nama; (4) akui setiap usaha; dan (5) jika layak dipelajari, maka layak pula dirayakan. Sejalan dengan pendapat Wena (2013: 161-162) prinsip-prinsip model quantum teaching dalam tabel sebagai berikut.

\begin{tabular}{|l|l|l|}
\hline No. & \multicolumn{1}{|c|}{ Prinsip } & \multicolumn{1}{|c|}{ Penerapan di kelas } \\
\hline 1 & $\begin{array}{l}\text { Segalanya berbicara: segalanya dari } \\
\text { lingkungan kelas hingga bahasa tubuh } \\
\text { guru, dari kertas yang dibagikan hingga } \\
\text { rancangan pembelajaran semuanya } \\
\text { mengirim pesan tentang belajar. }\end{array}$ & $\begin{array}{l}\text { Dalam hal ini guru dituntut untuk mampu } \\
\text { merancang/ mendesain sagala aspek yang } \\
\text { ada di lingkungan kelas maupun sekolah } \\
\text { sebagai sumber belajar bagi siswa. }\end{array}$ \\
\hline 2 & $\begin{array}{l}\text { Segalanya bertujuan: semua- nya terjadi } \\
\text { dalam kegiatan pembelajaran } \\
\text { mempunyai tujuan. }\end{array}$ & $\begin{array}{l}\text { Dalam hal ini setiap kegiatan belajar harus } \\
\text { jelas tujuannya. Tujuan pembelajaran ini } \\
\text { harus dijelaskan kepada siswa. }\end{array}$ \\
\hline 3 & $\begin{array}{l}\text { Pengalaman sebelum pemberian nama: } \\
\text { proses pembelajaran paling baik terjadi } \\
\text { ketika siswa telah mengalami informasi } \\
\text { sebelum memperoleh nama untuk apa } \\
\text { yang mereka pelajari. }\end{array}$ & $\begin{array}{l}\text { Dalam pembelajaran sesuatu (konsep, } \\
\text { rumus, teori, dan sebagainya) harus } \\
\text { dilakukan dengan cara memberi siswa tugas } \\
\text { pengalaman /eksperimen) terlebih dahulu. } \\
\text { Dengan tugas tersebut akhirnya siswa } \\
\text { mampu menyimpulkan sendiri konsep, } \\
\text { rumus, dan teori tersebut. Dalam hal ini } \\
\text { harus menciptakan simulasi konsep agar } \\
\text { siswa memperoleh pengalaman. }\end{array}$ \\
\hline 4 & $\begin{array}{l}\text { Akui setiap usaha: dalam setiap proses } \\
\text { pembelajaran siswa patut mendapatkan } \\
\text { pengakuan atas prestasi dan kepercayaan } \\
\text { dirinya. }\end{array}$ & $\begin{array}{l}\text { Guru harus mampu memberi penghargaan } \\
\text { atau pengakuan pada setiap usaha siswa. } \\
\text { Jika usaha siswa jelas salah, guru harus } \\
\text { mampu memberi pengakuan atau } \\
\text { pengharagaan walaupun usaha siswa salah, } \\
\text { dan secara perlahan membetulkan jawaban } \\
\text { siswa yang salah. Jangan mematikan } \\
\text { semangat siswa untuk belajar. }\end{array}$ \\
\hline 5 & $\begin{array}{l}\text { Jika layak dipelajari maka layak pula } \\
\text { dirayakan : perayaan dapat memberi } \\
\text { umpan balik mengenai kemajuan dan } \\
\text { meningkatkan asosiasi positif dengan } \\
\text { belajar. }\end{array}$ & $\begin{array}{l}\text { Dalam hal ini guru harus memiliki strategi } \\
\text { untuk memberi umpan balik (feedback) } \\
\text { positif yang dapat mendorong semangat } \\
\text { belajar siswa. Baik secara berkelompok } \\
\text { maupun secara individu. }\end{array}$ \\
\hline
\end{tabular}

ScienceEdu Vol. I. No. 1 Desember 2018

Received 10 October 2018 | Received in revised form 11 November2018| Accepted 25 November $2018 \mid$ Published online 31 December 2018 
Kelebihan dan Kelemahan Model Quantum Teaching:

\begin{tabular}{|l|l|}
\hline \multicolumn{1}{|c|}{ Kelebihan } & \multicolumn{1}{c|}{ Kelemahan } \\
\hline Melibatkan siswa secara holistik & Suasana meriuh bisa mengganggu kelas lain \\
\hline $\begin{array}{l}\text { Sesuai dengan rekomendasi pembelajaran } \\
\text { UNESCO }\end{array}$ & $\begin{array}{l}\text { Guru yang tidak bijaksana akan menyebabkan } \\
\text { kehilangan kehibawaan }\end{array}$ \\
\hline Merupakan Pembelajaran yang Interaktif & $\begin{array}{l}\text { Tidak semua guru mampu menciptakan } \\
\text { suasana yang riang tapi terarah }\end{array}$ \\
\hline $\begin{array}{l}\text { Sesuai dengan perkembangan anak yang } \\
\text { dinamis }\end{array}$ & \\
\hline Belajar sambil bermain & \\
\hline
\end{tabular}

Media Realia merupakan media nyata yang ada dilingkungan alam. Anitah (2008) berpendapat, "Realia atau disebut juga objek adalah benda yang sebenarnya dalam bentuk utuh, misalnya: orang, binatang, rumah dan sebagainya" (hlm. 25). Pendapat senada diungkapkan Wibawa dan Mukti (2001: 81) yang mengartikan realia adalah benda-benda nyata seperti apa adanya atau aslinya tanpa perubahan.

Pengertian lain dikemukakan oleh Uno yang berpendapat," Realia adalah benda nyata yang digunakan sebagai bahan ajar. Pemanfaatan media ini tidak harus selalu dihadirkan dalam ruangan kelas, tetapi dapat digunakan dalam suatu kegiatan observasi pada lingkungan" (2010: 125). Burden \& Byrd (1999:145) menjelaskan bahwa media realia adalah:

Realia are real things objects such as animals, plants, artifacts coins and minerals. As concrete objects, realia help provide direct purposeful expe-rience, which is at the bottom of Dale's Cone of Experience. Therefore, they are ideal for introducing students to a new subject. They give real-life meaning to otherwise abstract words.

(Realia adalah benda benda seperti hewan, tumbuhan, koin artefak dan mineral. Sebagai benda konkret, realia membantu memberikan pengalaman tujuan langsung, yang di bawah kerucut pengalaman. Oleh karena itu, realia ideal untuk memperkenalkan siswa untuk subjek baru. Realia memberi makna yang sebenarnya untuk kata-kata yang bersifat abstrak).

Kelebihan media realia a. Dapat memberikan kesempatan semaksimal mungkin pada siswa untuk mempelajari sesuatu ataupun melaksanakan tugas-tugas dalam situasi nyata.

b. Memberikan kesempatan kepada siswa untuk mengalami sendiri situasi yang sesungguhnya dan melatih keterampilan mereka dengan menggunakan sebanyak mungkin alat indera.

Kelemahan media realia

a. Membawa murid-murid ke berbagai tempat di luar sekolah kadangkadang mengandung resiko dalam bentuk kecelakaan dan sejenisnya.

b. Biaya yang diperlukan untuk mengadakan berbagai objek nyata kadangkadang tidak sedikit, apalagi ditambah dengan kemungkinan kerusakan dalam menggunakannya.

c. Tidak selalu dapat memberikan semua gambaran dari objek yang sebenarnya, seperti pembesaran, pemotongan, dan gambar bagian demi bagian, sehingga pengajaran harus didukung pula dengan media lain.

\section{METODE}

Teknik pengumpulan data yang digunakan untuk memperoleh bahan bahan yang relevan, dan sesuai dengan artikel ini, yaitu: (a) studi kepustakaan (b) angket. Data yang diperoleh pada artikel ini bersumber dari: (a) jurnal; (b) skripsi; (c) buku; (d) artikel. Kemudian data yang relevan tersebut digunakan untuk mendukung gagasan penulis, dan dijadikan dasar dalam 
pembuatan artikel model pembelajaran quantum teaching dalam meningkatkan keberanian berbicara siswa saat diskusi kelas dengan menggunakan media realia.

\section{HASIL DAN PEMBAHASAN}

Pengujian angket dilakukan di SMP Negeri 3 Bondowoso, dengan variablenya pada kelas 9D, 9E, dan 9F. Kelas 9D terdiri dari 38 siswa, kelas 9E terdiri dari 36 siswa, dan 9F terdiri dari 32 siswa, jadi total siswa yang melakukan pengisian angket sekitar 106 siswa.

Dari hasil angket, pada pernyataan 1 yaitu; Saya suka berbicara didepan kelas, dari jumlah 106 siswa, sekitar 78 siswa tidak suka berbicara di depan kelas, sedangkan 28 siswa tidak, kemudian pernyataan 2 mengenai rasa kurang percaya diri siswa, 70 siswa menyatakan dalam pilihan angketnya bahwa mereka kurang percaya diri dalam berbicara di depan kelas, sedangkan 36 siswanya mengatakan percaya diri. Kemudian pada pernyataan mengenai keaktifan siswa, 67 siswa memilih tidak berani menanyakan kepada guru atau pada sesi tanya jawab saat presentasi, dan 39 siswa memilih berani bertanya. Kemudian pada pernyataan perbandingan belajar dalam ruangan dan luar ruangan, 35 siswa memilih belajar dalam ruangan, dan 71 memilih lebih suka belajar diluar ruangan. Pada pernyataan belajar menggunakan proyektor atau objek langsung/nyata, 59 siswa memilih belajar menggunakan proyektor, dan 47 memilih belajar menggunakan objek nyata. Kemudian pada pernyataan yang paling ditunggu tunggu adalah perbandingan tentang kesukaan siswa dalam kegiatan belajar mengajar berlangsung, 98 siswa memilih lebih suka guru menjelaskan materi daripada siswa yang aktif berpresentasi, diskusi, ini menandakan bahwa 96 siswa lebih suka pembelajaran terfokus pada guru atau disebut Student Learning Center, sedangkan 8 siswa lain memilih lebih suka pembelajaran yang terfokus pada siswa, Student Learning Center.

Dapat disimpulkan secara singkat bahwa siswa dengan metode belajar yang disukai oleh siswa adalah Teacher Learning Center, tapi dengan metode itu, maka siswa tidak akan dituntut untuk berani berbicara, berani berdiskusi, berani bertanya, tidak terlatih sejak awal. Oleh karena itu dibuat pada Studi Literatur ini tentang penggunaan Metode Quantum Teaching serta Media Realia

Tabel 1. Angket

\begin{tabular}{|l|l|l|l|l|l|}
\hline No. & \multicolumn{1}{|c|}{ Pernyataan } & STS & TS & S & SS \\
\hline 1. & Saya suka berbicara di depan saat diskusi kelas & & & \\
\hline 2. & Saya merasa kurang percaya diri ketika berbicara di depan kelas & & & \\
\hline 3. & $\begin{array}{l}\text { Ketika pembelajaran berlangsung, saat itu juga diberi tugas untuk } \\
\text { menjelaskan di depan, saya gugup dan tidak berani untuk bicara }\end{array}$ & & & \\
\hline 4. & $\begin{array}{l}\text { Ketika guru menjelaskan atau teman presentasi di depan, saya } \\
\text { sering mengajukan pertanyaan saat sesi tanya-jawab }\end{array}$ & & & \\
\hline 5. & $\begin{array}{l}\text { Ketika guru menjelaskan, saya fokus menyimak penjelasan guru } \\
\text { pada materi yang disampaikan }\end{array}$ & & & \\
\hline 6. & $\begin{array}{l}\text { Belajar dengan cara siswa yang mempresentasikan materi } \\
\text { memberi kesan menakutkan bagi saya }\end{array}$ & & & \\
\hline 7. & Saya sebih suka guru yang menjelaskan daripada siswa presentasi & $\begin{array}{l}\text { penarut saya, belajar dengan guru menjelaskan memberi } \\
\text { memahaman materi lebih baik daripada siswa yang }\end{array}$ & & & \\
\hline 8. & $\begin{array}{l}\text { Saya lebih suka guru menjelaskan di papan daripada } \\
\text { menggunakan Proyektor }\end{array}$ & & & \\
\hline 10. & $\begin{array}{l}\text { Saya lebih suka guru menggunakan Proyektor daripada } \\
\text { menggunakan Demonstrasi dengan alat peraga/ obyek nyata }\end{array}$ & & & \\
\hline
\end{tabular}

ScienceEdu Vol. I. No. 1 Desember 2018 


\begin{tabular}{|c|l|l|l|l|}
\hline 11. & $\begin{array}{l}\text { Saya lebih suka belajar di luar ruangan daripada di dalam ruangan } \\
\text { kelas, seperti mengamati bentuk daun tumbuhan secara langsung }\end{array}$ & & & \\
\hline 12. & $\begin{array}{l}\text { Dengan belajar di luar ruangan dapat memudahkan saya } \\
\text { memahami materi yang disampaikan }\end{array}$ & & \\
\hline 13. & $\begin{array}{l}\text { Dengan adanya pertanyaan yang diajukan oleh guru atau teman, } \\
\text { menumbuhkan keingintahuan saya akan jawaban dari pertanyaan } \\
\text { tersebut }\end{array}$ & & & \\
\hline 14. & Saya selalu bertanya apabila ada materi yang tidak saya pahami & & \\
\hline 15. & $\begin{array}{l}\text { Saya siap dididik untuk menambah keberanian berbicara saya di } \\
\text { depan kelas maupun di depan masyarakat nantinya }\end{array}$ & & \\
\hline
\end{tabular}

Hasil dari angket dirangkum secara singkat menjadi berikut:

Tabel 2. Simpulan Hasil Angket

\begin{tabular}{|c|l|c|c|}
\hline No. & \multicolumn{1}{|c|}{ Simpulan Pernyataan } & $\begin{array}{c}\text { Tidak } \\
\text { Setuju }\end{array}$ & Setuju \\
\hline 1 & Berani berbicara di depan kelas & 78 & 28 \\
\hline 2 & Merasa kurang percaya diri ketika berbicara di depan kelas & 36 & 70 \\
\hline 3 & $\begin{array}{l}\text { Memiilih bertanya ketika guru selesai menjelaskan atau sesi tanya } \\
\text { jawab dalam presentasi }\end{array}$ & 67 & 39 \\
\hline 4 & Memilih belajar di luar ruangan daripada di dalam ruangan & 71 & 35 \\
\hline 5 & Memilih belajar menggunakan proyektor daripada objek nyata & 47 & 59 \\
\hline
\end{tabular}

Pada penelitian yang relevan, terjadi peningkatan aktivitas siswa setelah pengunaan Model Pembelajaran Quantum Teaching, hal ini terjadi karena siswa merasa belajar sesuai dengan alamnya sehingga ia seperti sedang bermain walau sebenarnya adalah belajar, dengan Model Pembelajaran Quantum Teaching siswa merasa bahwa Pembelajaran yang ia terima menyenangkan, mereka terbawa untuk menumbuhkan semangat belajar, mengalami pembelajaran yang ringan seberat apapun pelajaran im, mereka terbiasa menamai setiap hal yang dijumpai, alami sehingga pengendapan materi lebih baik, mereka juga mendemonstrasikannya, mengulangi, dan merayakan. Mereka merasa dihargai sekecil apapun hasil yang ia buat, sehingga mereka termotivasi untuk lebih berusaha menjadi lebih baik (Saiman, 2008)

Peningkatan keaktifan siswa dalam pembelajaran dikarenakan penggunaan media realia. Hal ini didasari oleh penggunaan media realia yang bisa memberikan pengalaman langsung kepada peserta didik. Dengan menggunakan media realia siswa dapat menggunakan sebanyak mungkin alat indera. Seperti yang diungkapkan oleh Suparno (1998:66) yang mengartikan media realia adalah benda sebenarnya yang dimanfaatkan oleh guru untuk proses pembelajaran. Sehingga, selama proses pembelajaran berlangsung partisipasi aktif dari siswa akan tumbuh. Dengan menggunakan media realia siswa dapat berperan aktif dalam pembelajaran, seperti melihat, meraba, melakukan berbagai eksperimen, dan melaporkan hasil pengamatan. Sehingga pengalaman langsung yang dialami siswa oleh siswa menjadikan muncul perasaan penasaran sehingga merangsang siswa untuk bertanya, kemampuan siswa diperoleh dari suatu proses pengalaman belajar. Sehingga apabila kualitas proses belajar meningkat, maka hasil belajar juga akan meningkat. 
Penggunaan media realia bukan hanya membuat proses pembelajaran lebih aktif, tetapi juga membantu siswa menyerap materi belajar lebih mendalam dan utuh.

Penggunaan media realia dapat memperjelas suatu materi. Hal ini disebabkan adanya pengalaman langsung yang dialami siswa dengan menggunakan media realia saat pembelajaran berlangsung. Media realia membuat pembelajaran yang abstrak lebih konkret sehingga dapat memberikan kesan mendalam dan lebih lama tersimpan pada diri siswa. Meningkatnya keterlaksanaan metode pembelajaran quantum teaching tentunya berpengaruh dengan tingkat motivasi belajar siswa. Berdasarkan pada kajian teori siswa yang mempunyai motivasi belajar yang tinggi indikatornya adalah tekun dan ulet, percaya pada diri sendiri, berani mengemukakan pendapat, dan memiliki hasrat untuk berprestasi. Tingkat motivasi belajar siswa didapat dari hasil observasi dari lembar observasi ciri-ciri motivasi tinggi belajar siswa sikus I dan siklus II. Hasil dari pengamatan yang dilakukan pada siklus I dan siklus II, tingkat motivasi belajar siswa mengalami kenaikan. Peningkatan tingkat motivasi belajar dari ciri-ciri motivasi tinggi belajar siswa secara keseluruhan dalam kelompok menggunakan metode pembelajaran quantum teaching dapat dilihat pada tabel

\begin{tabular}{|c|l|c|c|}
\hline No & Kelompok & $\begin{array}{c}\text { Siklus } \\
\text { I }\end{array}$ & $\begin{array}{c}\text { Siklus } \\
\text { II }\end{array}$ \\
\cline { 3 - 4 } & & $\%$ & $\%$ \\
\hline 1. & Kelompok I & 62,5 & 87,5 \\
\hline 2. & Kelompok II & 66,76 & 100 \\
\hline 3. & $\begin{array}{l}\text { Kelompok } \\
\text { III }\end{array}$ & 62,5 & 93,75 \\
\hline 4. & $\begin{array}{l}\text { Kelompok } \\
\text { IV }\end{array}$ & 62,5 & 100 \\
\hline 5. & Kelompok V & 83,3 & 93,75 \\
\hline 6. & $\begin{array}{l}\text { Kelompok } \\
\text { VI }\end{array}$ & 62,5 & 91,67 \\
\hline 7. & $\begin{array}{l}\text { Kelompok } \\
\text { VII }\end{array}$ & 56,3 & 87,5 \\
\hline 8. & $\begin{array}{l}\text { Kelompok } \\
\text { VIII }\end{array}$ & 75 & 100 \\
\hline
\end{tabular}

Berdasarkan tabel di atas dapat diketahui persentase tingkat motivasi belajar siswa pada pelaksanaan metode pembelajaran quantum teaching, Data bersumber dari penelitian yang relevan oleh Danang Jumiyanto, penggunaan metode pembelajaran quantum teaching untuk meningkatkan motivasi belajar dan prestasi belajar siswa mata diklat gambar teknik di smk perindustrian yogyakarta 2011/2012. Dengan adanya motivasi belajar yang bertambah, prosentase siswa untuk berbicara, berpendapat, terutama diskusi di kelas akan bertambah.

Penelitian lain yang relevan pembelajaran dengan menggunakan metode quantum teaching, antara lain:

1. Penelitian yang dilakukan oleh Susi Anggoro Kasih (2012) tentang Peningkatan Prestasi Belajar Ilmu Pengetahuan Alam Melalui Media Realia Pada Siswa Kelas Vii Smpn 2 Menggala yang menyimpulkan bahwa penggunaan media realia yang bersumber dari lingkungan sekitar kehidupan mahasiswa dalam pembelajaran Ilmu Pengetahuan Alam Kelas VIIA dan VIIB SMPN2 Menggala dapat meningkatkan aktivitas belajar siswa dalam mengerjakan LKS, mencatat materi penting, mengajukan pertanyaan, berdiskusi, dan mengemukakan pendapatnya. Keberanian siswa mulai meningkat dengan pengalam belajar secara langsung. Peningkatan prestasi belajar siswa kelas VII SMPN 2 Menggala terjadi melalui pembelajaran dengan menggunakan media realia yang bersumber dari lingkungan sekitar siswa. Peningkatan jumlah siswa yang tuntas belajar dari siklus kesiklus juga tidak sama yakni pada kelas VIIA 17 siswa (53\%) pada siklus kesatu meningkat menjadi 23 siswa (72\%) pada siklus kedua meningkat lagi menjadi 32 siswa $(100 \%)$ pada siklus ketiga dan pada kelas VIIB 18 siswa (56\%) pada siklus kesatu meningkat menjadi 22 siswa (69\%) pada siklus kedua meningkat lagi menjadi 32 siswa (100\%) pada siklus ketiga. Hal ini menunjukkan bahwa media realia dapat 
meningkatkan keberanian siswa dalam berpendapat sehingga meningkatkan prestasi.

2. Penelitian yang dilakukan oleh Vera Jayanti (2009) tentang Pengaruh Pembelajaran Quantum Teaching Terhadap Hasil Belajar IPA Biologi Siswa Kelas VII SMPN 24 Surakarta Tahun Pelajaran 2008/2009 yang menyimpulkan bahwa ada perbedaan antara prestasi belajar biologi dengan menggunakan metode Quantum Teaching dengan metode konvensional dan berdasarkan hasil rata-rata juga diketahui bahwa rata-rata nilai prestasi belajar untuk metode Quantum Teaching sebesar 73,40 dan rata-rata nilai prestasi belajar untuk metode konvensional sebesar 60,55 hal ini berarti bahwa nilai rata-rata prestasi belajar dengan metode Quantum Teaching lebih baik bila dibandingkan dengan metode konvensional pada mata pelajaran biologi siswa kelas VII SMPN 24 Surakarta tahun pembelajaran 2008/2009.

\section{KESIMPULAN}

Untuk menyelesaikan masalah yang terkait dengan keaktivan siswa serta rendahnya keberanian siswa dalam mengungkapkan pendapatnya, berbicara di kelas, maka perlu dilakukan inovasi yang baik dengan melalui perencanaan maupun proses pembelajarannya, menggunakan model quantum teaching dan media realia. Quantum teaching dilakukan berdasarkan prinsip prinsipnya, serta guru yang melakukan quantum teaching juga harus guru yang bijaksana yang mampu mengendalikan kondisi dan situasi kelas agar tidak riuh, serta optimalisasi dengan media realia.

\section{DAFTAR PUSTAKA}

Anitah, S. (2008). Media Pembelajaran. Surakarta: LPP UNS dan Press.

Arsyad, Azhar. 2002. Media Pembelajaran. Jakarta: Raja Grafindo Persada. h.3
DePorter, Bobbi dkk. 2002. Quantum Teaching: Mempraktekkan Quantum Learning di ruang-ruang kelas. Bandung: Kaifa

Djamarah., Zain. 2002. Strategi Belajar Mengajar. Jakarta: Penerbit Rineka Cipta.

Jumiyanto, Danang. 2012. Penggunaan Metode Pembelajaran Quantum Teaching Untuk Meningkatkan Motivasi Belajar Dan Prestasi Belajar Siswa Mata Diklat Gambar Teknik Di Smk Perindustrian Yogyakarta 2011/2012. Skripsi.

Purnama, Unty Bany. 2014. Penggunaan Media Realia Untuk Meningkatkan Kualitas Proses Dan Hasil Belajar Ipa Materi Tanah. ISSN: 2337-8786

Saiman, Marwoto., Slameto. 2008. Model Pembelajaran Quantum Teaching untuk Meningkatkan Hasil Belajar Ips Kelas $V$ SDS Kalam Kudus Kecamatan Tebing Tinggi, Kabupaten Bengkalis.

Slameto. 2003. Belajar dan Faktor-faktor yang Mempengaruhinya. Jakarta: Penerbit Rineka Cipta.

Suparno, A. S. (1998). Pemanfaatan dan Pengembangan Sumber Belajar Pendidikan Dasar. Departemen Pendidikan dan Kebudayaan Direktorat Jenderal Pendidikan Tinggi.

Wibawa, B. \& Mukti, F. (2001). Media Pengajaran. Bandung: CV Maulana.

ScienceEdu Vol. I. No. 1 Desember 2018 